
\title{
$\angle S$ Research Square \\ Long-term Efficacy of GPi DBS for Cranio Facial Dystonia: a Retrospective Report of 13 Cases
}

\section{Haibo Ren}

Sichuan University and Nanchong Central Hospital

\section{Rong Wen}

The Second Affiliated Hospital of Chongqing Medical University

Wei Wang ( $\sim$ wcnsww@163.com)

Sichuan University West China Hospital https://orcid.org/0000-0002-3110-5767

\section{Denghui Li}

West China Hospital, Sichuan University

\section{Mengqi Wang}

West China Hospital, Sichuan University

\author{
Yuan Gao \\ West China Hospital, Sichuan University

\section{Yang Xu} \\ West China Hospital, Sichuan University

\section{Yang Wu} \\ West China Hospital, Sichuan University
}

\section{Original Article}

Keywords: Cranio Facial dystonia, Meige syndrome, deep brain stimulation, globus pallidus internus, LEAD-DBS

Posted Date: February 9th, 2021

DOI: https://doi.org/10.21203/rs.3.rs-194592/v1

License: (a) (1) This work is licensed under a Creative Commons Attribution 4.0 International License. Read Full License 


\section{Abstract}

Objective: This study evaluated the long-term efficacy of globus pallidus internus (GPi) deep brain stimulation (DBS) in the treatment of Cranio Facial dystonia (Meige syndrome) and investigated the correlation between the volume of tissue activated (VTA) of the GPi and each subregion and movement score improvement.

Methods: We retrospectively analyzed the clinical data of 13 patients with drug-refractory Meige syndrome who were treated with GPi DBS. Pre- and postoperative Burke-Fahn-Marsden Dystonia Rating Scale (BFMDRS) scores were compared. Relationships between preoperative baseline variables and improvement in the BFMDRS-Movement (BFMDRS-M) score were analyzed. LEAD-DBS software was used for three-dimensional reconstruction of the GPi and implanted electrodes. Correlations between the GPi-VTA and score improvement were analyzed.

Results: The average follow-up period was $36.6 \pm 11.0$ months (18-55 months). The improvements in the BFMDRS-M score were $58.2 \%$ and $54.6 \%$ at 3 months after stimulation and the final follow-up visit, respectively, and the improvements in the BFMDRS-Disability (BFMDRS-D) score were $53.6 \%$ and $51.7 \%$, respectively. At the final follow-up visit, the improvements in BFMDRS-M scores for the eye, mouth, and speech/swallowing were significant $(P<0.001)$. Age was an independent predictor of improvement in the BFMDRS-M score after DBS $(P=0.005)$. A decrease in the BFMDRS-M score had significant positive relationships with the GPi-VTA $(r=0.757, P=0.003)$.

Conclusions: GPi DBS is an effective method to treat drug-refractory Meige syndrome. LEAD-DBS software can be used as an effective aid for visualization programing after DBS.

\section{Introduction}

Meige syndrome is a segmental dystonia characterized by blepharospasm and involuntary contractions of muscles of the face and jaw. The first-line treatments include oral medications (anticholinergics, benzodiazepines, and baclofen) and injection of botulinum toxin. Surgical treatment becomes an option when conservative treatment is not effective. Deep brain stimulation (DBS) has been widely used to treat primary dystonia[5, 26, 27], but only a few studies on DBS for Meige syndrome are available[10, 16, 19, 20, 28, 32]. To evaluate the long-term efficacy and safety of globus pallidus internus (GPi) DBS in the treatment of Meige syndrome, we summarized the long-term follow-up data of 13 patients with Meige syndrome who underwent GPi DBS.

During the follow-up, the spatial relationships of the contact of the implanted intracranial electrodes with the GPi and its subregions can be directly visualized using LEAD-DBS, a reconstruction software[11]. The volume of tissue activated (VTA) of the GPi and its subregions can be directly calculated through electrical field simulations[6]. Analysis of the correlation between the VTA of the GPi and each subregion and Burke-FahnMarsden Dystonia Rating Scale (BFMDRS) scores can enhance post-DBS visualization programing.

\section{Materials And Methods}

\section{Clinical data}


We retrospectively analyzed the clinical data of 13 patients with drug-refractory Meige syndrome who were treated with GPi DBS in West China Hospital of Sichuan University from August 2014 to June 2018. There were five men and eight women, with an average age of $46.9 \pm 7.2$ years (range: $38-65$ years). The average course of disease was $9.2 \pm 2.1$ years (range: 6-13 years), and all symptoms manifested as blepharospasm and oromandibular dystonia. The initial symptom was present in the eye in 10 patients and in the mouth in 3 patients. The symptoms of muscle tension disorders progressed to the neck in 12 patients (Table 1). 
Table 1

The basic information of patients with Meige Syndrome.

\begin{tabular}{|c|c|c|c|c|c|c|}
\hline \multirow{2}{*}{$\begin{array}{l}\text { Case } \\
\text { NO, } \\
\text { sex }\end{array}$} & \multirow{2}{*}{$\begin{array}{l}\text { DU } \\
\text { (years) }\end{array}$} & \multirow{2}{*}{$\begin{array}{l}\text { AS } \\
\text { (years) }\end{array}$} & \multirow{2}{*}{$\begin{array}{l}\text { Follow-up } \\
\text { (Ms) }\end{array}$} & \multirow{2}{*}{$\begin{array}{l}\text { BFMDRS-M } \\
\text { Pre-op; 3ms; last FU }\end{array}$} & \multicolumn{2}{|c|}{ parameters at last follow-up } \\
\hline & & & & & $\begin{array}{l}\text { GPi right } \\
(\mu \mathrm{s}, \mathrm{Hz}, \mathrm{V})\end{array}$ & $\begin{array}{c}\text { GPi left } \\
(\mu \mathrm{s}, \mathrm{Hz}, \mathrm{V})\end{array}$ \\
\hline \multirow{3}{*}{$\begin{array}{l}1, \\
\text { male }\end{array}$} & 8 & 42 & 24 & $16 \rrbracket 6 \rrbracket 8$ & contact 1(-) & contact $9(-)$ \\
\hline & & & & & Case $(+)$ & Case $(+)$ \\
\hline & & & & & $120 \mu \mathrm{s}, 180 \mathrm{~Hz}, 2.9 \mathrm{v}$ & $130 \mu \mathrm{s}, 180 \mathrm{~Hz}, 3.2 \mathrm{v}$ \\
\hline \multirow{3}{*}{$\begin{array}{l}2, \\
\text { female }\end{array}$} & 10 & 47 & 32 & $13 \rrbracket 6 \rrbracket 4$ & contact $0(-) 1(-)$ & contact 9(-) \\
\hline & & & & & Case $(+)$ & Case $(+)$ \\
\hline & & & & & $90 \mu \mathrm{s}, 160 \mathrm{~Hz}, 3.0 \mathrm{v}$ & $120 \mu \mathrm{s}, 160 \mathrm{~Hz}, 2.5 \mathrm{v}$ \\
\hline \multirow{3}{*}{$\begin{array}{l}3, \\
\text { female }\end{array}$} & 11 & 38 & 26 & $18 \varangle 2.5 \bigotimes 10$ & contact $1(-)$ & contact $8(-) 9(-)$ \\
\hline & & & & & contact $0(+)$ & Case $(+)$ \\
\hline & & & & & $150 \mu \mathrm{s}, 135 \mathrm{~Hz}, 2.5 \mathrm{v}$ & $120 \mu \mathrm{s}, 135 \mathrm{~Hz}, 3.1 \mathrm{v}$ \\
\hline \multirow{3}{*}{$\begin{array}{l}4, \\
\text { male }\end{array}$} & 9 & 50 & 45 & $15 \rrbracket 13 \rrbracket 3.5$ & contact 1(-) & contact $8(-) 9(-)$ \\
\hline & & & & & Case $(+)$ & contact $10(+)$ \\
\hline & & & & & $120 \mu \mathrm{s}, 170 \mathrm{~Hz}, 3.2 \mathrm{v}$ & $90 \mu \mathrm{s}, 170 \mathrm{~Hz}, 2.8 \mathrm{v}$ \\
\hline \multirow{3}{*}{$\begin{array}{l}5, \\
\text { male }\end{array}$} & 8 & 41 & 48 & $14 \llbracket 5 \rrbracket 4.5$ & contact $0(-)$ & contact 9(-) \\
\hline & & & & & Case $(+)$ & Case $(+)$ \\
\hline & & & & & $70 \mu \mathrm{s}, 125 \mathrm{~Hz}, 3.8 \mathrm{v}$ & $80 \mu s, 125 \mathrm{~Hz}, 3.5 \mathrm{v}$ \\
\hline \multirow{3}{*}{$\begin{array}{l}\text { 6, } \\
\text { female }\end{array}$} & 12 & 44 & 49 & $17.5 \rrbracket 6 \bigotimes 7.5$ & contact $1(-) 2(-)$ & contact 8(-) \\
\hline & & & & & Case $(+)$ & Case $(+)$ \\
\hline & & & & & $160 \mu \mathrm{s}, 180 \mathrm{~Hz}, 3.4 \mathrm{v}$ & $140 \mu \mathrm{s}, 180 \mathrm{~Hz}, 3.1 \mathrm{v}$ \\
\hline \multirow{3}{*}{$\begin{array}{l}\text { 7, } \\
\text { female }\end{array}$} & 7 & 54 & 28 & $15 \llbracket 3 \rrbracket 12$ & contact $1(-)$ & contact $8(-) 9(-)$ \\
\hline & & & & & Case $(+)$ & Case $(+)$ \\
\hline & & & & & $130 \mu \mathrm{s}, 150 \mathrm{~Hz}, 3.1 \mathrm{v}$ & $110 \mu \mathrm{s}, 150 \mathrm{~Hz}, 2.6 \mathrm{v}$ \\
\hline \multirow{3}{*}{$\begin{array}{l}8, \\
\text { male }\end{array}$} & 13 & 65 & 38 & $20.5 \rrbracket 8 \bowtie 10$ & contact $0(-) 1(-)$ & contact $8(-), 9(-)$ \\
\hline & & & & & Case $(+)$ & contact $10(+)$ \\
\hline & & & & & $110 \mu \mathrm{s}, 160 \mathrm{~Hz}, 2.8 \mathrm{v}$ & $100 \mu \mathrm{s}, 160 \mathrm{~Hz}, 3.3 \mathrm{v}$ \\
\hline 9, & 7 & 42 & 35 & $14 \llbracket 1.5 \bigotimes 1.5$ & contact $0(-)$ & contact 8(-) \\
\hline
\end{tabular}




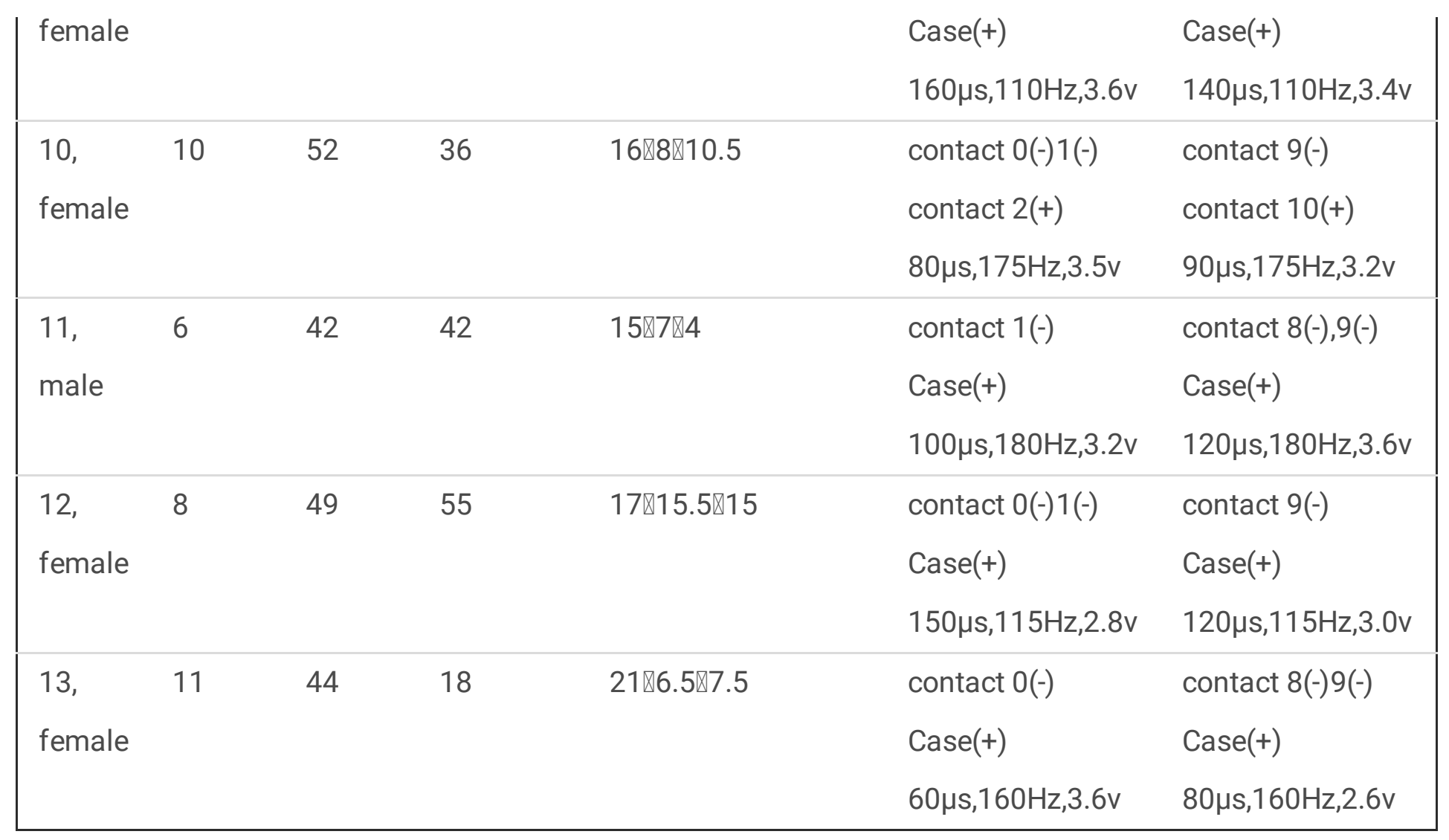

DU disease duration,AS age at surgery,FU follow-up time,Pre-op pre-operation,Ms months

A movement disorder specialist diagnosed this disease according to the diagnostic criteria of primary Meige syndrome[7]. All 13 patients received oral medication before surgery, and 11 patients received an intramuscular injection of botulinum toxin. Their symptoms were not alleviated indefinitely. All patients underwent brain magnetic resonance imaging (MRI) to rule out intracranial structural abnormalities. No history of brain trauma or cerebrovascular accidents was reported. All patients denied the use of antipsychotic drugs. No secondary dystonia with other etiologies was indicated.

\section{DBS surgical procedure}

One day before the operation, a 3.0-T MRI system (DISCOVERY, MR750 W, GE) was used to scan the brain. On the day of the operation, after installing the Leksell stereotactic head frame (Elekta Instrument AB, Sweden), the brain MRI scan was repeated using the same setting as previously. The images obtained from the two scans were fused to determine the target site in the GPi, which was usually at the site 1-3 mm anterior, 3-4 mm inferior, and 20-22 $\mathrm{mm}$ lateral to the midpoint of the anterior/posterior commissure. Under local anesthesia, the tip of the electrode (Model 3387, Medtronic) was placed at the bottom of the globus pallidus and at the upper edge of the optic tract. An intraoperative test stimulation was performed to determine the efficacy and detect any adverse effects (internal capsule effect, visual hallucinations) to confirm the accuracy of the target site. Under general anesthesia, an implantable pulse generator (IPG, ACTIVA RC, Medtronic) was placed subcutaneously under the clavicle. Postoperative MRI or computed tomography (CT) was performed to verify the location of the electrode within the GPi and to exclude intracranial hemorrhage.

\section{3D reconstruction of the GPi and the electrodes and VTA calculations}


Based on preoperative MRI and CT images, LEAD-DBS software was used for 3D reconstruction of the GPi and the implanted electrodes. The VTA was calculated by stimulation contact and stimulation parameters, which were input into the software during the follow-up to analyze correlations between the VTA of the GPi and its subregions and BFMDRS score changes.

\subsection{Imaging data}

Preoperative head MRI and postoperative head thin-slice CT images in DICOM format were collected after the operation.

\subsection{Transform format}

The program dcm2niix (Rorden, Li 2016) in the LEAD-DBS software or SPM 12 (The Wellcome Center for Human Neuroimaging, UCL Queen Square Institute of Neurology, London, UK) was used to convert DICOMformat image data into NifTl-format image data.

\subsection{Image fusion}

The NifTI-formatted images were imported into LEAD-DBS for image fusion.

\subsection{Image normalization and correction}

The fused images were normalized using Advanced Normalization Tools (Avants 2008), and the Coarse mask (Schonecker 2008) method was then used to correct the cortex and subcortex structures on the normalized images.

\subsection{Reconstruction of the lead trajectory}

The Medtronic 3387 electrode was used. Using previously fused and corrected images, the PaCER (Husch 2017) program was able to automatically extract the locations and directions of implanted electrodes. Moreover, the program could also determine the spatial relationships between the contact of the implanted electrodes and the GPi.

\subsection{D reconstruction}

The DISTAL Minimal (Ewert 2017) atlas was selected for 3D visualization. Lastly, the reconstructed results were used to show the corresponding electrode contact and GPi positions (Fig. 1).

\subsection{Calculation of the VTA}

LEAD-DBS displays a 3D spatial image of the electrical field of corresponding electrodes and a simulated active stimulation area, which are created by inputting stimulation contact and stimulation parameters into LEAD-DBS software (SimBio/FieldTrip (Horn 2017) method). By opening LEAD GROUP, the software can calculate the electric field stimulation zone and the VTA of the GPi and its subregions (Fig. 1). Based on different efferent nerves, the GPi is divided into the GPi sensory, GPi primary motor, GPi premotor, GPi postparietal, GPi occipital, GPi temporal, and GPi prefrontal regions (Fig. 2). Of these, the GPi sensorimotor (GPi sensory + GPi primary 
motor + GPi premotor) is considered a relay station for motor fibers and is also considered the best implantation area for GPi DBS for the treatment of Meige syndrome[7].

\subsection{Correlation analysis}

The appropriate stimulation contact and stimulation parameters were selected for each side of the brain after the procedure. Each patient's GPi-VTA is the sum of the left and right VTAs. Differences in BFMDRS scores before and after surgery were calculated based on the BFMDRS score at every follow-up visit. The correlation between the VTA of the GPi and each subregion and changes in BFMDRS scores was further analyzed.

\section{Efficacy evaluation}

Stimulation started 4 weeks after the operation, and the symptom changes and adverse effects corresponding to the stimuli of each contact point were documented to select the best contact. The stimulation parameters were gradually adjusted according to the patient's response to the stimulation. All scoring was performed by the same rater. The degree of dyskinesia was evaluated on the BFMDRS, which includes the BFMDRS-Movement scale (BFMDRS-M) (0-120 points) and BFMDRS-Disability Scale (BFMDRS-D) (0-30 points)[1]. The evaluation times were before surgery, 3 months after stimulation, and the final follow-up visit. During the follow-up period, time to symptom alleviation, oral medication, stimulation parameters, and complications were documented.

\section{Statistics}

The Mann-Whitney U test was used to compare the BFMDRS score after surgery with the baseline BFMDRS score before surgery. The Wilcoxon test was used to analyze the relationship between BFMDRS score improvement and preoperative baseline variables. The Spearman correlation test was used to analyze correlations between movement score changes and the VTA of the GPi and its subregions. The correlation coefficient was determined based on the $\mathrm{R}$ value. An $\mathrm{R}$ value greater than 0.5 was considered to indicate a significant correlation between the two variables, an $\mathrm{R}$ value between 0.3 and 0.5 was considered to indicate a weak correlation between the two variables, and an $\mathrm{R}$ value $<0.3$ was considered to indicate no correlation between the two variables. $\mathrm{P}<0.05$ was considered statistically significant. SPSS 23.0 statistical software was used for statistical analysis.

\section{Results}

\section{BFMDRS score improvement}

The average follow-up period was $36.6 \pm 11.0$ months (range: 18-55 months). Three months after stimulation, the BFMDRS-M score decreased by an average of $58.2 \%$ compared to the baseline before surgery $(16.3 \pm 2.4 \mathrm{vs}$. $6.8 \pm 3.9, P=0.000)$, and the BFMDRS-D score decreased by an average of $53.6 \%$ compared to baseline ( $6.2 \pm$ 1.8 and $2.8 \pm 1.1, P=0.000)$. As of the final follow-up visit, the BFMDRS-M score had decreased by an average of $54.6 \%$ compared with baseline $(16.3 \pm 2.4$ vs $7.5 \pm 3.9, P=0.000)$, and the BFMDRS-D score had decreased by an average of $51.7 \%(6.2 \pm 1.8$ vs $3.5 \pm 1.5, \mathrm{P}=0.001)$ (Table 2$)$. 
Table 2

BFMDRS outcomes in 13 patients with Meige Syndrome.

\begin{tabular}{|c|c|c|c|c|c|c|c|}
\hline Scale & Pre-op & $\begin{array}{l}3 \text { Ms } \\
\text { Post-op }\end{array}$ & Imp\% & P Value & Last follow-up & Imp\% & P Value \\
\hline $\begin{array}{l}\text { BFMDRS-M } \\
(0-40)\end{array}$ & $16.3 \pm 2.4$ & $6.8 \pm 3.9$ & $58.2 \%$ & $0.000 *$ & $7.5 \pm 3.9$ & $54.6 \%$ & $0.000 *$ \\
\hline $\begin{array}{l}\text { Eye } \\
(0-8)\end{array}$ & $5.9 \pm 1.4$ & $2.3 \pm 1.7$ & $59.3 \%$ & $0.000 *$ & $2.5 \pm 1.7$ & $56.8 \%$ & $0.000 *$ \\
\hline Mouth(0-8) & $4.9 \pm 1.9$ & $1.7 \pm 1.8$ & $69.7 \%$ & $0.001 *$ & $2.0 \pm 1.8$ & $61.5 \%$ & $0.002^{*}$ \\
\hline $\begin{array}{l}\text { Speech } \\
\text { /Swallow(0-16) }\end{array}$ & $3.5 \pm 1.0$ & $1.5 \pm 0.9$ & $50.6 \%$ & $0.000 *$ & $1.6 \pm 1.0$ & $51.9 \%$ & $0.000 *$ \\
\hline $\operatorname{Neck}(0-8)$ & $2.0 \pm 1.3$ & $1.2 \pm 0.7$ & $34.3 \%$ & 0.077 & $1.2 \pm 0.8$ & $35.9 \%$ & 0.081 \\
\hline BFMDRS-D $(0-30)$ & $6.2 \pm 1.8$ & $2.8 \pm 1.1$ & $53.6 \%$ & $0.000 *$ & $3.5 \pm 1.5$ & $51.7 \%$ & $0.001^{\star}$ \\
\hline Pre-op pre-operatio & ost-op po & eration, & p imp & ement,M & honths & & \\
\hline * means $P<0.05$ & & & & & & & \\
\hline
\end{tabular}


Table 3

Characteristics of the other related studies.

\begin{tabular}{|c|c|c|c|c|c|c|}
\hline Author \& year & No.of cases & Target & $\begin{array}{c}\text { FU } \\
\text { 『years } \rrbracket\end{array}$ & $\begin{array}{l}\text { Pre-op } \\
\text { BFMDRS-M }\end{array}$ & $\begin{array}{l}\text { Post-op } \\
\text { BFMDRS-M }\end{array}$ & $\begin{array}{l}\text { BFMDRS-M } \\
\text { Imp(\%) }\end{array}$ \\
\hline $\begin{array}{l}\text { Reese R } \\
\text { et al.[16],2011 }\end{array}$ & 12 & GPi & $38.8 \pm 21.7$ & $21.4 \pm 3.2$ & $9.8 \pm 4.1$ & $53 \%$ \\
\hline $\begin{array}{l}\text { Sako W } \\
\text { et al.[19],2011 }\end{array}$ & 5 & GPi & $49.4 \pm 43.7$ & $22.2 \pm 12.4$ & $3.1 \pm 1.4$ & $86 \%$ \\
\hline $\begin{array}{l}\text { Wang } X \\
\text { et al.[27],2016 }\end{array}$ & 4 & GPi/STN & $68.8 \pm 39.2$ & $16.9 \pm 5.0$ & $6.4 \pm 5.3$ & $62.1 \%$ \\
\hline $\begin{array}{l}\text { Sobstyl M } \\
\text { et al.[20],2017 }\end{array}$ & 6 & GPi & $31 \pm 20.9$ & $23.7 \pm 6.7$ & $11.0 \pm 3.0$ & $53.6 \%$ \\
\hline $\begin{array}{l}\text { Zhan S } \\
\text { et al.[31],2018 }\end{array}$ & 14 & STN & $28.5 \pm 16.5$ & $19.3 \pm 7.6$ & $5.5 \pm 4.5$ & $74 \%$ \\
\hline $\begin{array}{l}\text { Horisawa S } \\
\text { et al.[10],2018 }\end{array}$ & 16 & GPi & $66.6 \pm 42.1$ & $16.3 \pm 5.7$ & $6.7 \pm 7.6$ & $58.9 \%$ \\
\hline
\end{tabular}

At the final follow-up visit, regarding the individual BFMDRS-M scores, the score for the eye had decreased by an average of $56.8 \%(5.9 \pm 1.4$ to $2.5 \pm 1.7, P=0.000)$, the score for the mouth had decreased by an average of $61.5 \%$ ( $4.9 \pm 1.9$ to $2.0 \pm 1.8, P=0.002)$, the score for speech and swallowing had decreased by an average of $51.9 \%(3.5 \pm 1.0$ to $1.6 \pm 1.0, P=0.000)$, and the score for the neck had decreased by an average of $35.9 \%(2.0 \pm$ 1.3 to $1.2 \pm 0.8, P=0.081$ ) (Table 2 ).

\section{Predictors of DBS efficacy}

The Wilcoxon test was used to analyze the relationships between BFMDRS-M score improvement and baseline variables before surgery. Only age was a predictor of improvement in the BFMDRS score after DBS surgery (age, $P=0.005$; sex,$P=0.414$; course of disease $P=0.705$; follow-up period, $P=0.655$; $B F M D R S-M$ score before operation: $P=1.000)$.

\section{Follow-up for programming}

The follow-up for programming showed that stimulating the first or second contact at the bottom of the electrode produced the best clinical effect. The time to symptom alleviation was 5.6 days (range: 1-14 days) after stimulation, and the effect gradually stabilized. The stimulation parameters at the final follow-up visit were as follows: average pulse width $113 \mu \mathrm{s}(60-160 \mu \mathrm{s})$, average frequency $153 \mathrm{~Hz}(110-180 \mathrm{~Hz})$, and average 
voltage $3.1 \mathrm{~V}(2.5-3.8 \mathrm{~V})$ (Table 1). As of the final follow-up visit, three patients were taking a small amount of benzodiazepines, and no patient required treatment with botulinum toxin injections.

\section{GPi-VTA and the difference in BFMDRS scores}

The VTA is the sum of VTAs of the left and right sides of the brain. The GPi-VTA is mainly concentrated in the GPi sensory region, the GPi primary motor region, and the GPi premotor region. The average GPi-VTA, GPi sensor-VTA, GPi primary motor-VTA, and GPi premotor-VTA were $493 \pm 117.1 \mathrm{~mm} 3,90.6 \pm 35.5 \mathrm{~mm} 3,168.3 \pm$ $48.7 \mathrm{~mm} 3$, and $182.3 \pm 48.1 \mathrm{~mm} 3$, respectively. As of the latest follow-up, the BFMDRS-M score and the BFMDRS-D score decreased by an average of $8.77 \pm 3.47$ and $2.69 \pm 1.32$, respectively, compared to the preoperative baseline scores. Among the BFMDR-M scores of different sites, the score for the eyes decreased by an average of $3.38 \pm 1.79$, the score for the mouth decreased by an average of $2.84 \pm 1.60$, the score for speech and swallowing decreased by an average of $1.85 \pm 1.46$, and the score for the neck decreased by an average of $0.85 \pm 0.69$ (Table 4). 
Table 4

The basic information of VTA and the difference between the BFMDRS score of each part

\begin{tabular}{|c|c|c|}
\hline & Mean \pm Standard deviation & The median(Interquartile spacing) \\
\hline \multicolumn{3}{|l|}{ VTA (mm3) } \\
\hline GPi & $493 \pm 117.1$ & $518(219)$ \\
\hline GPi sensory & $90.6 \pm 35.5$ & $88(70)$ \\
\hline GPi primarymotor & $168.3 \pm 48.7$ & 164(92) \\
\hline GPi premotor & $182.3 \pm 48.1$ & 168(95) \\
\hline GPi sensorimotor & $265.2 \pm 85.6$ & $226(165)$ \\
\hline GPi postparietal & $111.6 \pm 60.9$ & $88(127)$ \\
\hline GPi occipital & $42.3 \pm 26.3$ & $42(36)$ \\
\hline GPi temporal & $4.2 \pm 8.2$ & $0(7.5)$ \\
\hline GPi prefrontal & $22.1 \pm 19.7$ & $18(40)$ \\
\hline \multicolumn{3}{|l|}{ Score difference } \\
\hline BFMDRS-M & $8.77 \pm 3.47$ & $9.5(4.50)$ \\
\hline Eye & $3.38 \pm 1.79$ & $3.0(3.0)$ \\
\hline Mouth & $2.84 \pm 1.60$ & $2.50(3.25)$ \\
\hline Speech/Swallow & $1.85 \pm 1.46$ & $2.0(1.0)$ \\
\hline Neck & $0.85 \pm 0.69$ & $1.0(1.0)$ \\
\hline BFMDRS-D & $2.69 \pm 1.32$ & $2.0(2.0)$ \\
\hline \multicolumn{3}{|c|}{ Score difference:difference in scores between before surgery and at the last follow-up } \\
\hline VTA volume of tis & activated & \\
\hline
\end{tabular}

\section{Correlations of the GPi-VTA with BFMDRS scores (Table 5)}

The decrease in the BFMDRS-M score was significantly correlated with the GPi-VTA and the subregional VTA. The decrease in the BFMDRS-M score was significantly positively correlated with the GPi-VTA $(r=0.757, P=$ $0.003)$, GPi sensory-VTA $(r=0.812, P=0.001)$, GPi primary motor-VTA $(r=0.726, P=0.005)$, GPi sensorimotorVTA $(r=0.713, P=0.006)$, GPi occipital-VTA $(r=0.843, P=0.000)$, and GPi temporal-VTA $(r=0.655, P=0.015)$. 
Table 5

The correlation between VTA and the BFMDRS score difference of each part.

\begin{tabular}{|c|c|c|c|c|c|c|}
\hline & BFMDRS-M & Eye & Mouth & $\begin{array}{l}\text { Speech/ } \\
\text { Swallow }\end{array}$ & Swallow & BFMDRS-D \\
\hline & R;P Value & R;P Value & R;P Value & $R ; P$ Value & R;P Value & R;P Value \\
\hline GPi & $0.757 ; 0.003^{*}$ & $0.441 ; 0.131$ & $0.345 ; 0.249$ & $0.800 ; 0.001 *$ & $0.232 ; 0.446$ & $0.426 ; 0.146$ \\
\hline GPi sensory & $0.812 ; 0.001^{\star}$ & $0.462 ; 0.112$ & $0.516 ; 0.071$ & $0.775 ; 0.002^{\star}$ & $0.401 ; 0.175$ & $0.521 ; 0.068$ \\
\hline $\begin{array}{l}\text { GPi } \\
\text { primarymotor }\end{array}$ & $0.726 ; 0.005^{\star}$ & $0.368 ; 0.216$ & $0.373 ; 0.209$ & $0.757 ; 0.003^{*}$ & $0.296 ; 0.326$ & $0.393 ; 0.184$ \\
\hline GPi premotor & $0.542 ; 0.056$ & $0.48 ; 0.097$ & $0.091 ; 0.766$ & $0.724 ; 0.005^{\star}$ & $0.123 ; 0.689$ & $0.15 ; 0.624$ \\
\hline $\begin{array}{l}\text { GPi } \\
\text { sensorimotor }\end{array}$ & $0.713 ; 0.006^{\star}$ & $0.424 ; 0.149$ & $0.419 ; 0.155$ & $0.703 ; 0.007^{\star}$ & $0.089 ; 0.772$ & $0.494 ; 0.086$ \\
\hline $\begin{array}{l}\text { GPi } \\
\text { postparietal }\end{array}$ & $0.349 ; 0.242$ & $-0.22 ; 0.47$ & $0.278 ; 0.358$ & $0.670 ; 0.012^{\star}$ & $0.206 ; 0.5$ & $0.314 ; 0.295$ \\
\hline GPi occipital & $0.843 ; 0^{*}$ & $0.581 ; 0.037^{\star}$ & $0.338 ; 0.259$ & $0.651 ; 0.016^{\star}$ & $0.33 ; 0.271$ & $0.472 ; 0.104$ \\
\hline GPi temporal & $0.655 ; 0.015^{\star}$ & $0.243 ; 0.424$ & $0.241 ; 0.428$ & $0.512 ; 0.074$ & $0.391 ; 0.186$ & $0.282 ; 0.351$ \\
\hline $\begin{array}{l}\text { GPi } \\
\text { prefrontal }\end{array}$ & $0.541 ; 0.056$ & $0.173 ; 0.573$ & $0.141 ; 0.646$ & $0.754 ; 0.003^{\star}$ & $0.546 ; 0.054$ & $0.266 ; 0.379$ \\
\hline \multicolumn{7}{|c|}{$\mathrm{GPi}$ sensorimotor ${ }^{\mathrm{D}}=\mathrm{GPi}$ sensory $+\mathrm{GPi}$ primarymotor $+\mathrm{GPi}$ premotor, $\mathrm{R} r$ Value } \\
\hline & & & & & & \\
\hline
\end{tabular}

The decrease in the eye score was significantly correlated only with the GPi occipital-VTA $(r=0.581, P=0.037)$.

The decrease in speech and swallowing scores was significantly positively correlated with the GPi-VTA $(r=$ $0.800, P=0.001)$, GPi sensory-VTA $(r=0.775, P=0.002)$, GPi primary motor-VTA $(r=0.757, P=0.003)$, GPi premotor-VTA $(r=0.724, P=0.005)$, GPi sensorimotor-VTA $(r=0.703, P=0.007)$, GPi occipital-VTA $(r=0.651, P=$ $0.016)$, and GPi prefrontal-VTA $(R=0.754, P=0.003)$.

\section{Adverse events}

At the final follow-up, poor efficacy was observed in two patients (BFMDRS-M score improvement $<30 \%[10]$ ). Postoperative CT imaging fusion showed no obvious deviation of the electrode from the intended target site. One of the patients only had 5-month symptom alleviation after stimulation. The symptoms in this patient relapsed to the preoperative baseline level and were not alleviated after multiple programming adjustments. One patient had dystonia in the right upper limb that was not present before the operation. In addition, during programming adjustment, two patients developed a facial twitch, and one patient developed dysarthria. These symptoms subsided after adjusting the stimulation parameters. One patient had an infection in the pulse generator pouch 1.5 years after surgery. The pulse generator was removed, and the pouch position was 
changed after anti-infective treatment. No intracranial hemorrhage was reported. No patient experienced slow movements or frozen gait.

\section{Discussion}

The etiology and pathophysiological mechanism of primary Meige syndrome are not fully understood. Some researchers have suggested that the pathogenesis may be related to disturbance of the function of the corticostriatal-globus pallidus-thalamic basal ganglia loop[14, 30].

Meige syndrome is a segmental dystonia. The first-line treatments include oral medication and intramuscular injection of botulinum toxin. If patients have severe symptoms and are not responsive to conservative treatment, DBS surgery may be considered. A few studies have found that GPi DBS can significantly relieve patients' movement symptoms and quality of life[10, 16, 19, 20, 28, 32]. In this study, 3 months after starting stimulation and at the final follow-up visit, the average decrease in the BFMDRS-M score was 58.2\% and $54.6 \%$, respectively, and the average decrease in the BFMDRS-D score was $53.6 \%$ and $51.7 \%$, respectively. These data are consistent with the results of previous studies[10, 16, 19, 20, 28, 32](Table 3).

After GPi DBS, the BFMDRS-M scores were improved by different amounts in different regions in patients with Meige syndrome. At the final follow-up visit in this study, the score for the eyes decreased by an average of $56.8 \%$, the score for the mouth decreased by an average of $61.5 \%$, the score for speech and swallowing decreased by an average of $51.9 \%$, and the score for the neck decreased by an average of $35.9 \%$. The BFMDRS$M$ scores for the eye, mouth and speech/swallowing were improved significantly $(P<0.001)$, whereas the BFMDRS-M score for the neck was not improved significantly $(P=0.081)$. These results were consistent with the results of previous studies[10,16,21]. In contrast, Chang JY et al. reported that the best improvement in BFMDRS-M score was observed in the neck assessment[9]. The inconsistent improvement in BFMDRS-M scores in different parts may be related to the position of the electrodes on the posterior ventral aspect of GPi. Muscle movement of the head and neck may correspond to different regions in the posterior ventral aspect of GPi. The tiny difference in the electrode location may lead to different degrees of improvement. A study with a larger sample size is needed to confirm that the stimulation of different subregions in the posterior ventral aspect of GPi can alleviate the symptoms of different segments of the head and neck.

A variety of factors may contribute to BFMDRS-M score improvements, including electrode location, stimulation contact, and stimulation parameters. In some studies, imaging techniques are used to explore the relationships of the locations of stimulation contact in the GPi and its subregions with the effectiveness of treatment. The study by Yao et al. included 15 patients with Meige syndrome who were treated with subthalamic nucleus (STN)-DBS and showed that the effective stimulation contacts were primarily located on the dorsolateral side of the STN. Improvement in motion symptoms was significantly positively correlated with the VTA in the STN motion zone[31]. Reich et al. analyzed 87 dystonia patients treated with GPi DBS and found that the GPi-VTA had some predictive value for improvement of movement symptoms[17]. The results of this study demonstrate that improvements in the BFMDRS-M score are closely related to the VTAs of movement and sensory areas. Positive correlations with the VTAs of other subregions were also identified, and the reasons may be related to anatomical and fibrotic connections in GPi subregions. Thus, LEAD-DBS can be an effective aid in postoperative DBS visualization programming. Larger stimulation parameters should be set for the GPi-VTA while ensuring no apparent side effects. 
Indeed, any indirect methods to visualise electrodes have some limitations[24]. The method used in our study has the following limitations: (1) Preoperative MRI needs to be registered into the standard atlas, which may change the patient's nuclear anatomical structure to some extent, and the reconstructed anatomical structure subregion does not completely conform to the patient's nuclear anatomical structure. (2) It is difficult to achieve $100 \%$ fusion of the preoperative MRI and the postoperative CT, which may lead to a certain deviation in the relative position of the electrode and the nucleus. (3) Although the process of the reconstructed electrode was registered by software and confirmed by the researchers, it was difficult to match the real electrode perfectly. (4) Based on the above three points, there might be some deviation between the reconstructed stimulus contacts and the nucleus structure. However, our team's previous study suggested that screening contacts using this method was consistent with blind screening contacts during testing symptom improvement. Therefore, this reconstruction method can reflect the relationship between contacts and the nucleus to some extent and may explain the efficacy of DBS to some extent using VTA. Our present study preliminarily explored the relationship between VTA of the nucleus subregion and the improvement of clinical symptoms, hoping to provide some theoretical guidance for postoperative visualization programming. We should admit that, at present, any indirect method to explore the relationship between stimulus contacts and nucleus structure has some limitations. Therefore, more studies are needed in the future to explore more powerful methods for us to reconstruct the nucleus and contacts.

It is controversial whether baseline factors (sex, age, course and severity of disease) are independent predictors of BFMDRS-M score after DBS surgery[2, 9]. Some studies have reported that baseline factors are not related to motor function improvement $[9,26,32]$. The study by Xin Wang et al., including 20 patients with Meige syndrome who underwent DBS, showed that the severity of the disease at onset and before surgery is an independent predictor of motor function improvement after DBS surgery[29]. In the current study, only age was an independent predictor of motor function improvement after surgery $(P=0.005)$. Sex, disease course, and BFMDRS-M score before surgery were not related to motor function improvement $(P>0.05)$.

In this study, after electrode implantation, most patients' symptoms were alleviated after surgery due to the effect of microdamage. The time required for symptom alleviation was 5.6 days (1-14 days) after starting stimulation, and the effect gradually stabilized. This study demonstrated that the ventral contact point of the electrodes (the lowest first or second contact point) with high-frequency stimulation greater than $100 \mathrm{~Hz}$ is associated with the best alleviation of motor symptoms. Two studies[19-20] reported that low-frequency stimulation $(60 \mathrm{~Hz})$ alleviated the motor symptoms of Meige syndrome. In this study, low-frequency stimulation (less than $100 \mathrm{~Hz}$ ) was performed on two patients with poor efficacy, and the movement disorder symptoms were not alleviated.

For patients with Meige syndrome who respond poorly to GPi DBS, STN DBS treatment can be used as a remedy. A few studies have suggested that STN DBS can be used to effectively treat primary dystonia, including Meige syndrome, to alleviate motor function symptoms[12-13, 15, 28, 32]. In 2018, Zhan S et al. reported 14 cases of STN DBS for the treatment of Meige syndrome. During an average follow-up period of $28.5 \pm 16.5$ months, the mean BFMDRS-M score improved by $74 \%$ (the pre- and post-DBS scores were $19.3 \pm 7.6$ and $5.5 \pm$ 4.5, respectively). The BFMDRS-D scores were $15.6 \pm 4.9$ and $6.1 \pm 3.5$ before and after the operation, respectively. The 36 -item Short-Form Health Survey score for quality of life was also significantly improved. 
STN DBS was associated with quicker symptom alleviation after stimulation, more convenient programming, and lower stimulus parameters than GPi DBS[32].

Good tolerance with few complications was observed in patients with Meige syndrome who underwent GPi DBS surgery. Common complications related to stimulation include limb twitching, dysarthria, and bradykinesia. Some studies have reported that patients undergoing GPi DBS treatment for dystonia develop bradykinesia, difficulty moving, and other symptoms similar to Parkinson's disease[3-4, 18, 22]. In addition, GPi DBS may cause cognitive and emotional changes and even serious adverse effects of the limbic system, such as mania, depression, and suicidal impulses[23, 25]. In 2006, Foncke EM et al. reported that two patients committed suicide 3 weeks and 14 months after undergoing GPi DBS for dystonia[8]. In this study, one patient had an infected pulse generator pouch, leading us to change its position. Two patients developed facial twitches, and one patient developed dysarthria. These symptoms subsided after adjusting the stimulation parameters.

\section{Study Limitations}

The shortcomings of this study include the lack of an evaluation of the effect of GPi DBS on cognition and emotion. This study was a retrospective study with a small sample size. Our team is conducting a prospective, multicenter, randomized controlled study to compare the alleviation of motor disorder symptoms, the improvement in quality of life, and the effect on emotional cognition between GPI DBS and STN DBS for the treatment of Meige syndrome, as well as to fully compare the efficacy and safety of DBS (two target points) (registration number: ChiCTR2000032852).

\section{Conclusion}

GPi DBS treatment for Meige syndrome can significantly alleviate the severity of dystonia and patient dysfunction. LEAD-DBS software can be used as an effective aid for visualization programing after DBS.

\section{Abbreviations}

GPi: globus pallidus internus

DBS: deep brain stimulation

VTA: volume of tissue activated

BFMDRS: Burke-Fahn-Marsden Dystonia Rating Scale

\section{Declarations}

\section{Authors' contributions}

All authors contributed to the study conception and design. Material preparation, data collection, and analysis were performed by Haibo REN, Rong Wen and Denghui Li. The first draft of the manuscript was written by Haibo REN and Rong Wen. Wei Wang, Denghui Li, Mengqi Wang, Yuan Gao, Yang Xu, and Yang Wu read and approved the final manuscript. 


\section{Funding}

This study was funded by 135 Project of Outstanding Development of West China Hospital, Sichuan University (No. ZY2017307).

\section{Availability of data and material}

The data used and/or analyzed during the current study are available from the corresponding author on reasonable request.

\section{Compliance with ethical standards}

\section{Conflict of interest}

The authors declare that they have no conflict of interest.

\section{Ethical approval}

The research protocol was approved by the Ethics Committee on Biomedical Research, West China Hospital of Sichuan University (No. 20202).

\section{Code availability}

Not applicable.

\section{Consent to participate}

Informed consent was obtained from all individual participants included in the study.

\section{Consent for publication}

Informed consent for publication was obtained.

\section{Open Access}

This article is distributed under the terms of the Creative Commons Attribution 4.0 International License (http://creativecommons.org/licenses/by/4.0/), which permits unrestricted use, distribution, and reproduction in any medium, provided you give appropriate credit to the original author(s) and the source, provide a link to the Creative Commons license, and indicate if changes were made.

\section{Declarations of interest}

This work was supported by 135 Project of outstanding development of west china hospital, Sichuan University (No. ZY2017307).

\section{References}

1. Burke RE, Fahn S, Marsden CD, Bressman SB, Moskowitz C, Friedman J (1985) Validity and reliability of a rating scale for the primary torsion dystonias. Neurology 35(1):73-77. https://doi.org/10.1212/wnl.35.1.73 
2. Bronte-Stewart H, Taira T, Valldeoriola F, Merello M, Marks WJ Jr, Albanese A, Bressman S, Moro E (2011) Inclusion and exclusion criteria for DBS in dystonia. Mov Disord 26 (Suppl 1):S5-S16.

https://doi.org/10.1002/mds.23482

3. Berman BD, Starr PhA, Marks WJ, Ostrem JL (2009) Induction of bradykinesia with pallidal deep brain stimulation in patients with cranial-cervical dystonia. Stereotact Funct Neurosurg 87(1):37-44. https://doi.org/10.1159/000195718

4. Blahak C, Capelle HH, Baezner H, Kinfe TM, Hennerici MG, Krauss JK (2011) Micrographia induced by pallidal DBS for segmental dystonia: a subtle sign of hypokinesia?J Neural Transm(Vienna) 118 (4):549553. https:// doi.org/10.1007/s00702-010-0544-y

5. Deng Z, Pan Y, Zhang C, Zhang J, Qiu X, Zhan S, Li D, Sun B (2018) Subthalamic deep brain stimulation in patients with primary dystonia: A ten-year follow-up study. Parkinsonism Relat Disord 55:103110. https://doi.org/10.1016/j.parkreldis.2018.05.024

6. Duffley G, Anderson DN, Vorwerk J, Dorval AD, Butson CR (2019) Evaluation of methodologies for computing the deep brain stimulation volume of tissue activated. J Neural Eng 16(6):066024. https://doi.org/10.1088/1741-2552/ab3c95

7. Faulstich ME, Carnrike CL Jr, Williamson DA (1985) Blepharospasm and Meige syndrome: a review of diagnostic, aetiological and treatment approaches. J Psychosom Res 29(1):89-94. https://doi.org/10.1016/0022-3999(85)90012-1

8. Foncke EM, Schuurman PR, Speelman JD (2006) Suicide after deep brain stimulation of the internal globus pallidus for dystonia. Neurology 66(1):142-143. https://doi.org/10.1212/01.wnl.0000191328.05752.e2

9. Ghang JY, Lee MK, Jun SM, Ghang CG (2010) Outcome of Pallidal Deep Brain Stimulation in Meige Syndrome. J Korean Neurosurg Soc 48(2):134-138. https://doi.org/10.3340/jkns.2010.48.2.134

10. Horisawa S, Ochiai T, Goto S, Nakajima T, Takeda N, Kawamata T, Taira T (2018) Long-term outcome of pallidal stimulation for Meige syndrome. J Neurosurg 130(1):84-89. https://doi.org/10.3171/2017.7.JNS17323

11. Horn A, Kühn AA ( 2015) Lead-DBS: a toolbox for deep brain stimulation electrode localizations and visualizations. Neuroimage 107:127-135. https://doi.org/10.1016/j.neuroimage.2014.12.002

12. Limotai N, Go C, Oyama G, Hwynn N, Zesiewicz T, Foote K, Bhidayasiri R, Malaty I, Zeilman P, Rodriguez R, Okun MS (2011) Mixed results for GPi-DBS in the reatment of cranio-facial and cranio-cervical dystonia symptoms. J Neurol 258(11):2069-2074. https://doi.org/10.1007/s00415-011-6075-0

13. Lyons MK, Birch BD, Hillman RA, Boucher OK, Evidente VG (2010) Long-term follow-up of deep brain stimulation for Meige syndrome. Neurosurg Focus 29(2):E5. https://doi.org/10.3171/2010.4.FOCUS1067

14. Moyer JT, Danish SF, Finkel LH (2011) Deep brain stimulation:anatomical, physiological, and computational mechanisms. Network 22(1-4):186-207. https://doi.org/10.3109/0954898X.2011.638356

15. Ostrem JL, Markun LC, Glass GA, Racine CA, Volz MM, Heath SL, de Hemptinne C, Starr PA (2014) Effect of frequency on subthalamic nucleus deep brain stimulation in primary dystonia. Parkinsonism Relat Disord 20(4):432-438. https://doi.org/10.1016/j.parkreldis.2013.12.012

16. Reese R, Gruber D, Schoenecker T, Bäzner H, Blahak C, Capelle HH, Falk D, Herzog J, Pinsker MO, Schneider GH, Schrader C, Deuschl G, Mehdorn HM, Kupsch A, Volkmann J, Krauss JK (2011) Long- 
term clinical outcome in meige syndrome treated with internal pallidum deep brain stimulation. Mov Disord 26(4):691-698. https://doi.org/ 10.1002/mds.23549

17. Reich MM, Horn A, Lange F, Roothans J, Paschen S, Runge J, Wodarg F, Pozzi NG, Witt K, Nickl RC, Soussand L, Ewert S, Maltese V, Wittstock M, Schneider GH, Coenen V, Mahlknecht P, Poewe W, Eisner W, Helmers AK, Matthies C, Sturm V, Isaias IU, Krauss JK, Kühn AA, Deuschl G, Volkmann J (2019) Probabilistic mapping of the antidystonic effect of pallidal neurostimulation: a multicentre imaging study. Brain 142(5):1386-1398. https://doi.org/10.1093/brain/awz046

18. Risch V, Staiger A, Ziegler W, Ott K, Schölderle T, Pelykh O, Bötzel K (2015) How does GPiDBS Affect Speech in Primary Dystonia? Brain Stimul 8(5):875-880.

https://doi.org/10.1016/j.brs.2015.04.009

19. Sako W, Morigaki R, Mizobuchi Y, Tsuzuki T, Ima H, Ushio Y, Nagahiro S, Kaji R, Goto S (2011) Bilateral pallidal deep brain stimulation in primary Meige syndrome. Parkinsonism Relat Disord 17(2):123-125. https://doi.org/10.1016/j.parkreldis.2010.11.013

20. Sobstyl M, Brzuszkiewicz-Kuźmicka G, Zaczyński A, Pasterski T, Aleksandrowicz M, Ząbek M (2017) Longterm clinical outcome of bilateral pallidal stimulation for intractable craniocervical dystonia (Meige syndrome). Report of 6 patients. J Neurol Sci 383:153-157. https://doi.org/10.1016/j.jns.2017.10.017

21. Sensi M, Cavallo MA, Quatrale R, Sarubbo S, Biguzzi S, Lettieri C, Capone JG, Tugnoli V, Tola MR, Eleopra R (2009) Pallidal stimulation for segmental dystonia: long term follow up of 11 consecutive patients. Mov Disord 24(12):1829-1835. https://doi.org/10.1002/mds.22686

22. Schrader C, Capelle HH, Kinfe TM, Blahak C, Bäzner H, Lütjens G, Dressler D, Krauss JK (2011) GPiDBS may induce a hypokinetic gait disorder with freezing of gait in patients with dystonia. Neurology 77(5):483-488. https://doi.org/10.1212/WNL.0b013e318227b19e

23. Saleh C, Okun MS (2008) Clinical review of deep brain stimulation and its effects on limbic basal ganglia circuitry. Front Biosci 13:5708-5731. https://doi.org/10.2741/3111

24. Saleh C (2010) Knowing the limitations of applied deep brain stimulation technology for a clearer understanding of clinical outcomes. J Neurol Sci 292(1-2):119. https://doi.org/10.1016/j.jns.2010.01.027

25. Tolosa E, Kulisevsky J, Fahn S (1988) Meige syndrome: primary and secondary forms. Adv Neurol 50:509515.

26. Vidailhet M, Vercueil L, Houeto JL, Krystkowiak P, Benabid AL, Cornu P, Lagrange C, Tézenas du Montcel S, Dormont D, Grand S, Blond S, Detante O, Pillon B, Ardouin C, Agid Y, Destée A, Pollak P (2005) Bilateral deep-brain stimulation of the globus pallidus in primary generalized dystonia. N Engl J Med 352(5):459467. https://doi.org/10.1056/NEJMoa042187

27. Volkmann J, Wolters A, Kupsch A, Müller J, Kühn AA, Schneider GH, Poewe W, Hering S, Eisner W, Müller JU, Deuschl G, Pinsker MO, Skogseid IM, Roeste GK, Krause M, Tronnier V, Schnitzler A, Voges J, Nikkhah G, Vesper J, Classen J, Naumann M, Benecke R (2012) Pallidal deep brain stimulation in patients with primary generalised or segmental dystonia:5-year follow-up of a randomised trial. Lancet Neurol 11(12):10291038. https://doi.org/10.1016/S1474-4422(12)70257-0

28. Wang X, Zhang C, Wang Y, Liu C, Zhao B, Zhang JG, Hu W, Shao X, Zhang K (2016) Deep brain stimulation for craniocervical dystonia (Meige Syndrome): a report of four patients and a literature-based analysis of its treatment effects. Neuromodulation 19(8):818-823. https://doi.org/10.1111/ner.12345 
29. Wang X, Mao Z, Cui Z, Xu X, Pan L, Liang S, Ling Z, Yu X (2019) Predictive factors for long-term clinical outcomes of deep brain stimulation in the treatment of primary Meige syndrome.J Neurosurg 5:1-

9. https://doi.org/10.3171/2019.1.JNS182555

30. Yang J, Luo C, Song W, Guo X, Zhao B, Chen X, Huang X, Gong Q, Shang HF (2014) Diffusion tensor imaging in blepharospasm and blepharospasm oromandibular dystonia. J Neurol 261(7):1413-1424. https://doi.org/10.1007/s00415-014-7359-y

31. Yao C, Horn A, Li N, Lu Y, Fu Z, Wang N, Aziz TZ, Wang L, Zhang S (2019) Post-operative electrode location and clinical efficacy of subthalamic nucleus deep brain stimulation in Meige syndrome. Parkinsonism Relat Disord 58:40-45. https://doi.org/10.1016/j.parkreldis.2018.05.014

32. Zhan S, Sun F, Pan Y, Liu W, Huang P, Cao C, Zhang J, Li D, Sun B (2018) Bilateral deep brain stimulation of the subthalamic nucleus in primary Meige syndrome.J Neurosurg 128(3):897-902.

https://doi.org/10.3171/2016.12.JNS16383

\section{Figures}

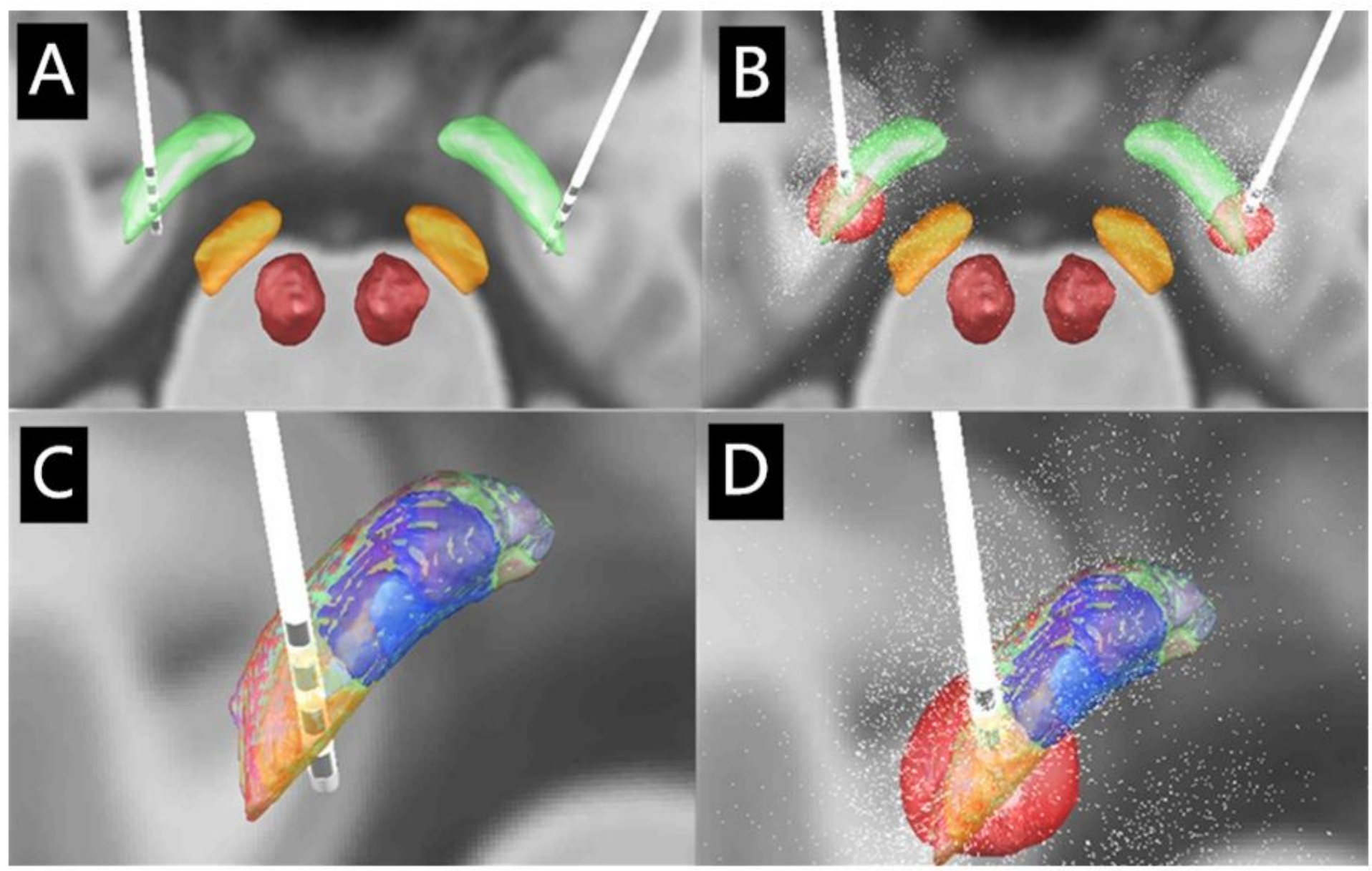

\section{Figure 1}

3D reconstruction of GPi and electrode and VTA of GPi and subregions. (A) Position of bilateral electrodes in GPi in Patient 1; (B) VTA of GPi with Case(+) Contact $9(-)$ at voltage $3.2 \mathrm{~V}$ and Case(+) Contact $1(-)$ at voltage $2.9 \mathrm{~V}$; (C) The left electrode and GPi and subregions; (D) VTA of GPi and subregion with Case(+) Contact $9(-)$ at 
voltage $3.2 \mathrm{~V}$. The red spheres in the figure represent VTA, the white dots represent the distribution diagram of the stimulation electric field, and the different colors of GPi represent the different subregions.

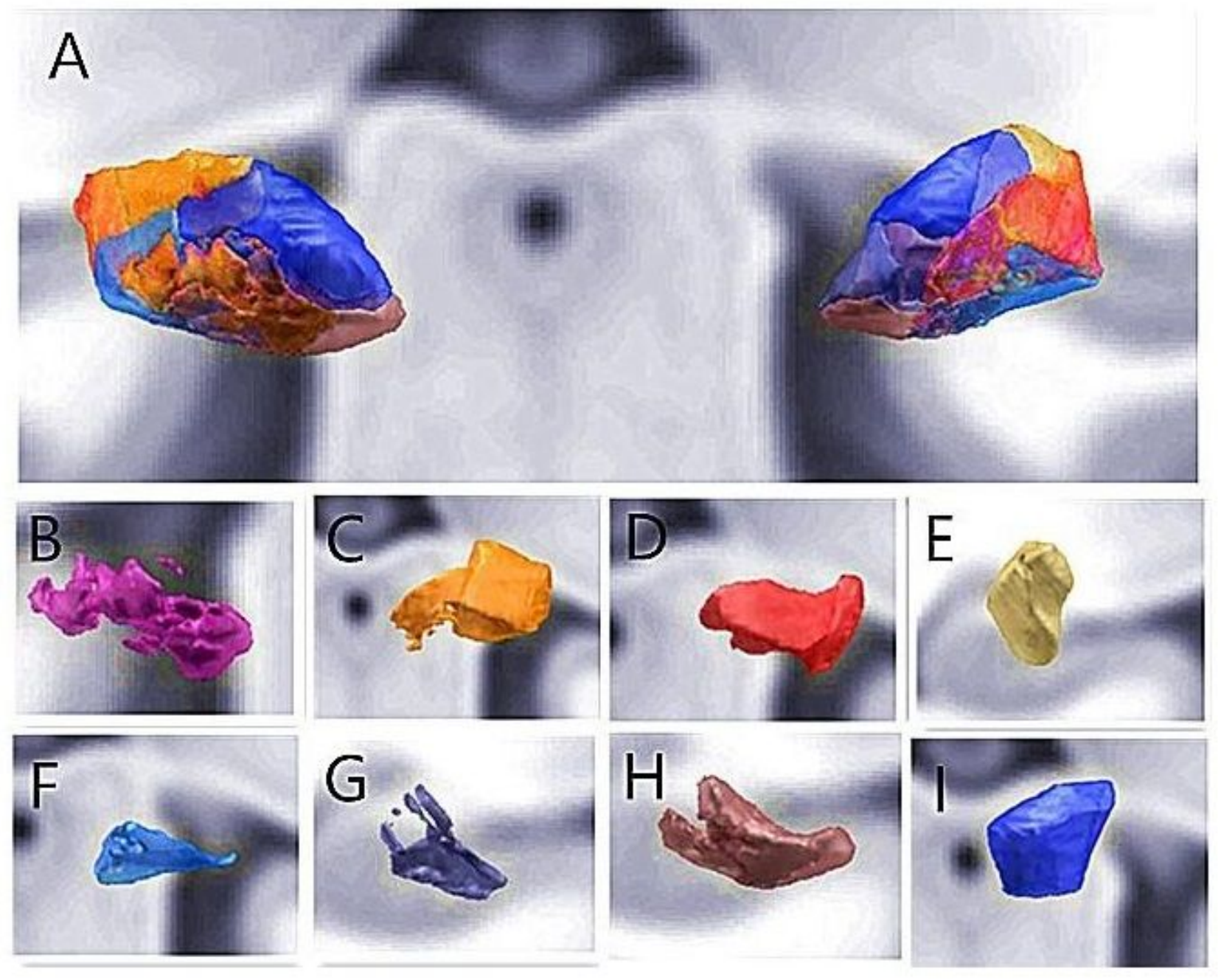

Figure 2

GPi and subregions. (A) GPi; (B) GPi sensory; (C) GPi sensorimotor; (D) GPi primary motor; (E) GPi premotor; (F) GPi postparietal; (G) GPi occipital; (H) GPi temporal; (I) GPi prefrontal. 